\title{
A fundação do Partido Democrático Trabalhista (PDT) no exílio
}

\section{The foundation of the Democratic Labor Party (PDT) in exile}

\author{
Teresa Cristina Schneider Marques* \\ Leandro Pereira Gonçalves**
}

\begin{abstract}
Resumo: O presente artigo analisa a fase genética do Partido Democrático Trabalhista (PDT), um partido político de cunho nacional, mas fundado em Portugal por Leonel Brizola e outros brasileiros durante o exílio. A particular origem do PDT nos leva a refletir sobre o papel do exílio imposto às suas lideranças para a compreensão das primeiras escolhas que marcam a trajetória do partido. A pesquisa indicou que o contexto no qual o PDT foi criado - marcado pela redemocratização portuguesa e pelo jogo transnacional em que os exilados são inseridos ao deixar o país - influenciou as suas principais lideranças e criou as condições para o surgimento do chamado "socialismo moreno".

Palavras-chave: Leonel Brizola. Trabalhismo. Exílio. Partido Democrático Trabalhista.

Abstract: This article analyzes the process that markes the origins of the Democratic Labor Party (PDT), a political party founded in Portugal by Leonel Brizola and other Brazilians in exile. The foundation of PDT leads us to reflect on the role that mandatory exile had on its leaders in regards to understanding the first decisions that defined the trajectory of the party. The research showed that the context in which the PDT was created-marked by the Portuguese re-democratization and the transnational context in which the exiled were inserted away from their original country - influenced its main leaders and the emergence of the so-called "brown socialism".
\end{abstract}

Keywords: Leonel Brizola. Labourism. Exile. Democratic Labor Party.

*Doutora em Ciência Política pela Universidade Federal do Rio Grande do Sul (Ufrgs, Porto Alegre, RS, Brasil) com estágio doutoral no Institut d'Études Politiques de Paris (Sciences Po, Paris, França). Professora adjunta do PPG em Ciências Sociais da Pontifícia Universidade Católica do Rio Grande do Sul (Pucrs, Porto Alegre, Brasil)<teresa.marques@pucrs.br>.

**Doutor em História pela Pontifícia Universidade Católica de São Paulo (PUC-SP, São Paulo, Brasil) com estágio (Junior Visiting Fellow) no Instituto de Ciências Sociais da Universidade de Lisboa (ICS-UL, Lisboa, Portugal). Professor adjunto do PPG em História da Pontifícia Universidade Católica do Rio Grande do Sul (Pucrs, Porto Alegre, Brasil) <leandro. goncalves@pucrs.br>.

Civitas, Porto Alegre, v. 16, n. 3, p. 399-416, jul.-set. 2016 


\section{Introdução}

A fundação do Partido Democrático Trabalhista (PDT) se dá em um contexto particular, se comparado com os demais partidos que passaram a atuar no cenário político brasileiro após o processo de transição democrática. Em 1979, ainda durante o exílio, Leonel Brizola, um dos principais opositores ao regime militar brasileiro, organizou em Portugal uma reunião com intelectuais e militantes trabalhistas brasileiros. Como resultado da reunião, foi divulgada a Carta de Lisboa, aprovada com o intuito de marcar a refundação do Partido Trabalhista Brasileiro (PTB), que havia sido extinto em 1965 pelo Ato Institucional n. 2 (AI-2), que estabeleceu o bipartidarismo (Alves, 2005). Contudo, Brizola perdeu a legenda para Ivete Vargas - sobrinha-neta do expresidente Getulio Vargas - em um processo judicial concluído em 1980. Apesar dessa derrota, manteve-se a Carta de Lisboa enquanto marco fundador do novo partido trabalhista, marcado pela fundação de um "novo trabalhismo", posteriormente chamado, por Darcy Ribeiro, de "socialismo moreno", como destacam diversos estudos (Sento-Sé, 2007; Vainfas, 2007; Batistella, 2013). A Carta apresenta os princípios programáticos do PDT e o tornou o único partido brasileiro fundado no exílio, centralizado na figura de Leonel Brizola.

A particular origem do PDT e a centralidade assumida por Leonel Brizola no processo de (re)fundação do partido nos levam a refletir, neste artigo, acerca do papel do caráter transnacional do exílio imposto às suas lideranças para a compreensão das suas primeiras escolhas. Alinhamo-nos a Panebianco (2005) ao destacar que a história e o modo de surgimento do partido importam para compreender a consolidação da organização. Para esse autor, "inevitáveis especificidades fazem do modelo originário de um partido um unicum histórico" (Panebianco, 2005, p. 92). No caso do momento fundacional do PDT, além do papel carismático desempenhado por Brizola, as específicas condições impostas pelo exílio à atuação política das lideranças parecem importar para a compreensão das primeiras escolhas do partido, sobretudo aquelas que representaram uma adaptação do trabalhismo aos novos tempos. Dessa forma, a influência do caráter transnacional assumido pelo jogo político destacado por Tilly e Tarrow (2008) pode apontar caminhos para compreender o impacto da esfera internacional na esfera nacional, especificamente nos partidos políticos, por meio da análise do seu impacto nas ações das lideranças.

Portanto, o presente artigo tem como principal objetivo a compreensão da fase genética do PDT e do papel desempenhado pelas lideranças portuguesas como limitadoras do alcance político do carisma de Brizola. Diante da especificidade do contexto de surgimento do PDT, propomos um 
diálogo entre a sociologia das organizações proposta por Panebianco (2005) e a perspectiva histórico-institucionalista proposta por Tilly e Tarrow (2008). Objetiva-se refletir sobre a possibilidade de formação de um partido com caráter carismático puro no exílio. Posteriormente, busca-se compreender o contexto português e analisar a maneira como as cumplicidades e alianças estabelecidas por Brizola e demais líderes trabalhistas com grupos, pessoas e entidades influenciaram o conteúdo programático de um partido que, embora fundado em Portugal, vislumbrava a atuação legal no Brasil. Para tanto, maior ênfase é atribuída à análise das redes nas quais Brizola foi inserido e da Carta de Lisboa, assim como dos novos significados atribuídos pelos seus autores a temas como democracia, trabalhismo e direitos humanos.

\section{Partidos políticos e exílio: a influência do jogo transnacional na esfera doméstica}

A organização em partidos políticos e o voto são formas de atuação política institucionalizada. Como tal, dificilmente são oferecidas aos exilados, mesmo em tempos de transnacionalismo, isto é, em tempos de fortalecimento de atores não estatais na esfera internacional (Kaiser, 1971). Em geral, essa forma de organização é garantida aos cidadãos de regimes democráticos. Para Dahl (1997), um dos pressupostos da democracia é a permissão para que a oposição se organize de forma aberta e legal em partidos políticos que possam competir em eleições livres e justas pelo governo.

De acordo com Panebianco (2005), o processo de construção de um partido é complexo e, não raro, é resultado de agremiação de uma pluralidade de grupos políticos distintos. Para o autor, diferentes fatores afetam esse processo, como, por exemplo, a origem por penetração ou difusão territorial, a presença ou ausência de uma organização patrocinadora e a presença ou ausência de uma liderança carismática.

Os partidos carismáticos puros são raros. Diante do papel central assumido por Brizola na organização, diversos estudos apontam que o PDT é um desses casos. Segundo D’Araújo (1996, p. 12), “o PDT era o partido de Brizola, e essa paternidade era mais importante do que seu nome oficial". Para Panebianco (2005, p. 97), um partido carismático pode ser identificado pelo fato de "ser formado por um líder que se coloca como um idealizador e o intérprete incontroverso de um conjunto de símbolos políticos (as metas ideológicas originárias do partido) que se tornam inseparáveis de sua pessoa".

Se por um lado é claro o papel carismático desempenhado por Brizola enquanto líder do partido na sua fase genética, por outro também são claras as restrições impostas à sua atuação política no exílio. Conforme colocado, 
formas institucionalizadas de participação política são negadas aos refugiados e asilados: ao conquistar o direito ao asilo, estabelecido no $14 \mathrm{O}$ artigo da Declaração Universal dos Direitos Humanos de 1948, o perseguido político perde os direitos expressos nos $19^{\circ}$ e $20^{\circ}$ artigos do mesmo documento, que versam sobre o direito à liberdade de expressão, opinião política e organização pacífica (Jubilut, 2007). Portanto, restrições institucionais adicionais são acrescentadas à ação coletiva no exílio (Marques, 2011). Além disso, custos sociais adicionais são acrescentados à atuação política dos exilados, pois, além da perda da condição de cidadão, ele perde o contato com a rede militante com a qual estava habituado a atuar.

Tais restrições não impediram que Leonel Brizola estivesse à frente da reunião de grupos políticos distintos em torno do projeto de recriação do PTB ainda durante o exílio em Portugal. Em 1978, após 13 anos de exílio no Uruguai e cerca de cinco meses nos Estados Unidos, Leonel Brizola partiu para Portugal, incentivando, segundo Freire (2010), o deslocamento de uma leva de exilados para esse país europeu.

Grande parte dos exilados que migraram com esse fluxo fez parte do "encontro dos trabalhistas do Brasil com trabalhistas no exílio" em 17 de junho de 1979 em Lisboa. Tal reunião marcou o início do processo fundacional do Partido Democrático Trabalhista (PDT). Embora seu início tenha se dado em terras estrangeiras, no documento assumido pelo partido enquanto seu marco fundador, o partido não se propôs a ser uma organização partidária transnacional, ou mesmo um partido com uma "atuação transnacional":

Reconhecendo que é urgente a tarefa de libertação do nosso povo, nós, brasileiros que optamos por uma solução trabalhista, nos encontramos em Lisboa. E se o fizemos fora do País, é porque o exílio arbitrário e desumano impediu este Encontro no lugar mais adequado: a Pátria brasileira. A tarefa de organizar com nosso povo um Partido verdadeiramente nacional, popular e democrático é cada vez mais premente (Carta de Lisboa, 1979, p. 1).

O documento deixa claro que a atuação em território brasileiro é a primeira e mais central escolha da organização partidária que então emergia, ainda que nesse momento tal atuação ainda não fosse legal. $O$ fato de ter surgido no exílio não tornou o PDT um "partido transnacional", uma vez que mesmo as definições mais simplistas destacam a atuação além do território nacional (Forti Neto, 2013). No caso do PDT, podemos considerá-lo enquanto um partido nacional, criado no exílio em torno do carisma de Brizola e em virtude da sua pressa para retornar ao jogo político. Não raro, essa pressa 
acompanha o exilado, sobretudo quando ele é um personagem político com significativa trajetória no seu país de origem.

Assim, questionamos: é possível a criação de um partido carismático puro no exílio? Isto é, é possível que um personagem político possua tamanho carisma a ponto de não precisar negociar a imposição da sua vontade mesmo excluído legalmente do processo político? Segundo Panebianco (2005, p. 98), há uma diferença entre o carisma situacional e o carisma puro:

O carisma situacional se diferencia do carisma puro por uma capacidade menor do líder de plasmar a organização de acordo com a sua vontade e o seu arbítrio [...]. A diferença está no fato de que, enquanto no caso do carisma puro o partido não tem uma existência autônoma do líder, ficando inteiramente à sua mercê, no caso do carisma situacional, apesar do enorme poder do líder, o partido não é simplesmente uma criatura sua, mas nasce de uma pluralidade de estímulos e impulsos e, portanto, outros agentes podem garantir para si um certo grau de controle sobre a zona de incerteza da organização.

É importante destacar que, se enquanto cidadão, o ator político deve negociar suas possibilidades de atuação e suas reivindicações com o estado, que determina "as regras do jogo" por meio do regime político, por sua vez, o exilado também deve negociar com o estado acolhedor. Segundo Tilly e Tarrow (2008), é o regime que estabelece as regras do jogo interno e decide quais ações políticas são indicadas, toleradas ou proibidas. Apenas a partir dessa negociação, os exilados podem ultrapassar as restrições a eles impostas. Além disso, é importante destacar que, no exílio, ${ }^{1}$ essa negociação é influenciada pelo país expulsor. $\mathrm{Na}$ era transnacional, o exilado se vê forçado a negociar também com a sociedade transnacional, isto é, com atores políticos não estatais, tornando o jogo político no exílio um jogo com estrutura quádrupla (Roniger, 2010).

Essa necessidade imposta aos líderes exilados de negociar com o estado de acolhida, com o estado expulsor e com outros atores políticos nos leva a questionar a pureza do caráter carismático assumido pelo PDT em sua fase inicial. A pesquisa indica que, durante a chamada fase genética, as restrições impostas à atuação política de Leonel Brizola enquanto exilado limitaram

\footnotetext{
${ }^{1}$ Além dos exilados pelo regime militar, destacamos os atingidos pelo Estado Novo no Brasil, entre eles o integralista Plínio Salgado. De 1939 a 1946, o líder dos integralistas oficialmente não era um exilado político, apesar de discursar que era refém da ditadura getulista. Mesmo distante, organizou a fundação do Partido de Representação Popular em 1945, a versão integralista no âmbito da democracia (Gonçalves, 2012).
} 
o papel político do seu carisma, o que o aproximou da situação de líder carismático situacional. Assim, o presente artigo parte da hipótese de que, em Portugal, Brizola se viu forçado a negociar, sobretudo com as autoridades portuguesas, o surgimento da organização em pleno exílio.

Nesse sentido, cabe destacar a importância da compreensão do contexto de surgimento de partidos políticos para análise do seu desenvolvimento. Mesmo autores clássicos para o estudo de partidos, que focam na questão da organização interna, reconhecem a importância de alguns fatores externos. Destacamos Robert Michels que, em Sociologia dos partidos políticos (1911), segundo Ribeiro (2012, p. 42), considera "as diferenças nacionais" ao se referir de forma genérica às " "tradições históricas', fatores ligados a 'raça', caráter nacional, hábitos do povo etc.".

Além das tradições históricas e dos hábitos nacionais, em seu estudo sobre o Partido Social Democrata Alemão (SPD), Michels aponta a importância das primeiras escolhas do partido político para a compreensão do seu desenvolvimento (Michels apud Ribeiro, 2012). Essa visão é compartilhada por Panebianco (2005), que destaca a relevância da compreensão do processo fundacional. As primeiras escolhas, segundo o autor, são adaptadas ao contexto à medida que novas exigências - tanto institucionais quanto culturais (que afetam o "mercado eleitoral") - são impostas aos partidos. A adaptação, diferente da substituição dos objetivos iniciais por outros, permite manter a identidade coletiva da organização. Diante disso, há uma tendência entre os partidos políticos em manter os objetivos iniciais, ainda que adaptados aos novos contextos que se apresentam.

Sendo assim, parece fundamental não negligenciar a importância do contexto de surgimento do partido para o seu desenvolvimento. No caso do PDT, sua formação ocorre em torno de uma liderança carismática então exilada - Leonel Brizola - e da necessidade de negociar com as elites locais e com a esfera transnacional. Para compreender a negociação entre os atores políticos envolvidos no processo de fundação do PDT, parece fundamental analisar o contexto português, destacando como esse país se relacionava com o regime militar brasileiro.

\section{$O$ contexto português: democratização, bases para o novo trabalhismo e relações com o Brasil}

Para compreender a ida de Leonel Brizola para Portugal em 1978, é preciso retomar a análise a partir do processo de democratização, que tem início em 25 de abril de 1974, quando ocorre a deposição do regime ditatorial 
do Estado Novo, vigente desde 1933. A Revolução dos Cravos encerrou uma das mais longas ditaduras do século 20, eliminando assim o regime corporativista liderado por António de Oliveira Salazar (1933-1968) e seu sucessor, Marcello Caetano (1968-1974). A transição democrática foi um período de incertezas no qual diversas vertentes políticas buscaram o controle do novo governo português em um período de acentuada "crise do estado, potenciada pela simultaneidade entre democratização e descolonização do último império colonial europeu" (Pinto, 2015, p. 36).

O processo revolucionário português é bastante singular, principalmente por contar com a intervenção democrática dos capitães na transição, caracterizando, portanto, o movimento como, possivelmente, o único do século 20. O caminho que levou Portugal da ditadura à democracia foi realizado através de uma ruptura, ou seja, "sem qualquer pacto ou negociação entre a elite da ditadura e as posições" (Pinto, 2015, p. 37).

Tal contexto, marcado por uma ruptura singular a favor da liberdade democrática, também se mostrou um momento em que era preciso manter relações com o Brasil. Assim, o predomínio da esquerda no poder político português não criava obstáculos para o relacionamento com a direita, que estava no centro poder político brasileiro, mas se preparava para a transição democrática. Logo, estava sendo criado em Portugal o cenário perfeito para o desenvolvimento de uma política do exilado Leonel Brizola, que encontrou na liderança de Mário Soares o apoio central para o fortalecimento das suas ações.

Até 25 de abril de 1974, eram poucos os partidos e as organizações que haviam sobrevivido na clandestinidade. Entre eles, podemos citar o Partido Comunista Português (PCP), que foi fundado em 1921 e atravessou toda a ditadura. Em 25 de abril, era o partido mais organizado. A partir dessa data, há um fortalecimento significativo dos partidos, em razão do novo contexto de liberdade e da reabertura desse canal de participação. Assim, além dos comunistas, no processo democrático destacavam-se o Partido Socialista (PS), o Partido Popular Democrático (PPD) e o Centro Democrático Social (CDS). Com esses grupos, estabeleceu-se a política democrática portuguesa. Entretanto, foi através da esquerda portuguesa (PS e PCP) que ocorreram os primeiros debates políticos em busca da consolidação democrática.

Essa força pode ser notada na organização histórica vigente e, sobretudo, no apoio externo da social-democracia europeia (Secco, 2004). Nesse contexto, cabe destacar que o PS foi fundado em 19 abril de 1973 na Alemanha (Bad Münstereifel), a partir da antiga Acção Socialista Portuguesa (ASP). Desde então e até os dias atuais, tal associação esteve indissociavelmente ligada 
a Mário Soares, que desembarcou em Lisboa em 28 de abril de 1974, após exílio $^{2}$ em Paris (Rezola, 2011). A direita, mesmo saudosista do regime destruído, nada mais poderia fazer. Com isso, passam a apoiar e a defender a democracia portuguesa e a procurar dirigentes que não possuíam associações com o Estado Novo.

Em abril de 1975, foram realizadas as primeiras eleições livres e universais em Portugal, conferindo inédita força e legitimidade à via eleitoral. Isso significou um marco para o processo político português, até então caracterizado pela supremacia do poder revolucionário que se legitimou com a derrubada da ditadura (Rezola, 2011). Dessa forma, nas primeiras eleições democráticas da história de Portugal, os moderados foram vitoriosos, sendo o PS o primeiro partido a vencer uma eleição, seguido pelo PPD e CDS.

A partir de maio de 1975, a então evidente tensão entre legitimidade eleitoral e revolucionária se transformou em uma luta no terreno, traduzida em episódios de crescente tensão. No início do verão, o poder militar que gravitava em torno do primeiro-ministro, Vasco Gonçalves, muito próximo do PCP, pareceu dominar a situação. O poder militar contava ainda (no início do verão) com o apoio da extrema esquerda civil e militar.

Com o IV Governo Provisório, elementos da política internacional, incluindo a brasileira, interpretam as ações da esquerda portuguesa como uma ação em defesa soviética no âmbito da Guerra Fria. A radicalização política em Portugal fortaleceu-se com ações da extrema esquerda, tanto militar quanto civil. Essa política ficou conhecida como "verão quente" e tinha como proposta a nacionalização de diversos segmentos econômicos (Noronha, 2012). O verão quente foi um período de incertezas, principalmente em relação ao Brasil, pois "um novo fluxo migratório, desta vez composto por empresários e profissionais liberais, partia de Portugal para o Brasil, reforçando a percepção de que Lisboa estaria perdida para o comunismo" (Pinto, 2015, p. 39).

Nesse período, o contexto político almejado por Brizola passou a ser mais delineado, pois de forma constante, nos meios de comunicação, ocorriam críticas ao contexto ditatorial brasileiro e, ao mesmo tempo, ações de violência em representações brasileiras em Portugal passavam a ser alvo da esquerda, como ataques à Varig e ao Banco do Brasil - que tentou ser nacionalizado pelo governo português. As ações eram realizadas pelas autoridades portuguesas ou por exilados brasileiros em Portugal, que passaram a expressar com mais intensidade seu caráter ideológico, principalmente por existir um momento

${ }^{2}$ Mário Soares foi preso 12 vezes, sendo posteriormente deportado para São Tomé em 1968. Em 1970, foi exilado na França, onde ficou até 28 de abril de 1974, quando retornou para Portugal no "Comboio da Liberdade". 
favorável (Carvalho, 2014). Cabe destacar que o governo brasileiro não agia e não tinha nenhum tipo de força contra a política existente em Portugal.

A retomada ao caminho moderado que conduziria à normalização das relações bilaterais com o Brasil se deu apenas com a retomada do controle político pelas forças civis e conservadoras em 25 de novembro de 1975. As eleições presidenciais e legislativas de 1976 marcaram o caráter moderado da nova democracia portuguesa. O governo constitucional passou a ser chefiado pelo socialista Mário Soares, que esclareceu ter salvo Portugal do comunismo (Carvalho, 2014). Verifica-se que "durante o mesmo período desencadeou-se um processo de afastamentos políticos contra a esquerda [...]. Vários militantes de partidos de extrema esquerda e do PCP foram afastados das suas posições no aparelho de estado e nas empresas públicas" (Pinto, 2015, p. 50). Assim, o período marca o início do isolamento da extrema esquerda portuguesa.

No fim da década de 1970, havia um clima de reconciliação política marcada pelo controle do PS e pela liderança de Mário Soares. Buscavase, sobretudo, uma ordem moderada em Portugal e o reestabelecimento de algumas parcerias comerciais internacionais, tais como o retorno dos empresários portugueses radicados no Brasil. Identifica-se que Soares buscava a governabilidade e, com isso, conseguia o regresso de alguns exilados de direita para Portugal, principalmente empresários. Além disso, o período marcou a saída paulatina dos militares do poder e a consolidação partidária na cena política portuguesa, o que eliminou qualquer possibilidade de (re)criar alguma figura antiesquerdista (Pinto, 2015).

Quanto à relação entre Brasil e Portugal nesse momento, cabe destacar que a visão dos militares brasileiros era simplista em relação ao novo governo português. Mário Soares era visto pelo governo ditatorial brasileiro como a melhor alternativa, visto que havia receio do PCP e da ameaça comunista que ele representava (Carvalho, 2014). Se por um lado o primeiro-ministro não tinha simpatia do alto escalão do regime, por outro recebia constantemente elogios de parlamentares da Aliança Renovadora Nacional (Arena). Soares tentou se aproveitar dessa abertura para criar uma imagem mais moderada e assim buscar investidores, enquanto a Geisel interessava estabelecer o isolamento da linha dura, para dar início à transição gradual para a democracia.

A força ocidental no âmbito político do PS foi notada com mais propriedade em maio de 1977, quando Soares solicitou a entrada de Portugal na Comunidade Econômica Europeia (CEE), ampliando o leque ideológico existente no partido e criando uma cisão com o PCP. O ano de 1978, que marca o rápido, entretanto, definidor exílio de Brizola em Portugal, é crucial para os rumos políticos do PS de Soares. A sociedade portuguesa ainda possuía muitas 
dúvidas sobre a validade ou não do caminho que estava sendo tomado, como a questão do colonialismo e, principalmente, a entrada à CEE. Entretanto, os anos seguintes marcaram a consolidação da integração portuguesa na identidade europeia social-democrata, marcada pela valorização dos direitos humanos e pelo fortalecimento do estado do bem-estar social (Sento-Sé, 2007).

Assim, o país que Brizola encontrou ao desembarcar em Portugal em 1978 era uma nação livre, com aspirações democráticas, com debates através de uma esquerda ativa e, principalmente, preocupada em manter relações com o Brasil. O primeiro-ministro português e um dos principais líderes da Internacional Socialista, Mário Soares, foi peça-chave em Portugal para a abertura que o exilado precisava para o desenvolvimento da Carta de Lisboa. Segundo Freire (2010), Leonel Brizola recebia apoio político e material.

Verifica-se, portanto, que a escolha de Brizola por Portugal, que estava sob a liderança de Soares, não foi aleatória. Apesar de a partir de 25 de abril o fluxo de brasileiros em direção a Portugal ter aumentado, é certo que a política desse país para com os brasileiros era menos favorável, se comparada com a adotada pela França, país que acolheu a maior parte dos brasileiros após o golpe chileno (Marques, 2011). Além de ter negado muitos requerimentos de asilo, para alguns exilados o governo português "dava margem a uma situação de insegurança", ao permitir o monitoramento das suas atividades (Freire, 2010). Todavia, para um líder político como Brizola, o processo de acolhida foi diferente. Foi através das relações estabelecidas no âmbito da esquerda internacional que Brizola encontrou na sede do PS, em 1979, espaço para a reorganização do trabalhismo, com apoio do primeiro-ministro português. Resta compreender como Brizola deu um novo significado ao trabalhismo com o objetivo de aproveitar as oportunidades políticas abertas pela socialdemocracia em Portugal.

\section{Solidariedade no exílio: a Carta de Lisboa como resultado do jogo político transnacional}

A análise do contexto português evidencia que o país vivia um momento político marcado por algumas questões, dentre as quais destacamos: a crescente valorização da democracia e da participação política por meio de canais institucionalizados, como os partidos políticos, por exemplo, o que renovou as lideranças políticas; a reprovação de regimes políticos acusados de institucionalizar o uso da violência contra seus opositores; e o interesse pela retomada de parcerias comerciais vistas como fundamentais para o crescimento econômico e para a projeção internacional de Portugal nesse novo momento político do país. 
Esse quadro representou uma nova estrutura de oportunidades políticas para Brizola e outros exilados, tais como Miguel Arraes. Muito embora Portugal mantivesse uma postura ambígua quanto aos exilados, para um grupo seleto de brasileiros - sobretudo políticos e intelectuais - o exílio em Portugal representou uma projeção das suas ações políticas. Segundo Mário Soares (2011), em depoimento posterior:

Um belo dia, eu já era primeiro ministro em Portugal [...] há uma emergência, uma situação, o Brizola foi expulso do Uruguai, porque houve um incidente, refugiou-se na embaixada americana, mas eles só dão por algum tempo a possibilidade de ele estar e eu preciso de um passaporte. É evidente que nós damos o passaporte, isso é indiscutível, você veja lá que damos o passaporte, depois gostávamos de um congresso em Lisboa, o que é que você acha? Eu acho que nós somos do Partido Socialista e vocês são socialistas também, então faça o congresso do partido socialista.

O depoimento de Mário Soares evidencia que, mesmo em um período marcado pela emergência de uma "sociedade transnacional" e pelo uso massificado do exílio enquanto forma de exclusão política, as relações dos membros das elites exiladas com o estado acolhedor se mantiveram enquanto peça fundamental na equação exilar. A chegada de um líder da oposição à ditadura simpático ao novo líder português, em um contexto de abertura política no Brasil e pós-transição política em Portugal, ampliou sobremaneira a estrutura de oportunidades políticas dos exilados brasileiros.

Todavia, fica claro na fala de Mário Soares que essa ampliação é condicionada pelo regime e pelas redes encontradas no estado de acolhida. Isso fica evidente quando Soares admite que "sugeriu" um congresso de socialistas brasileiros em Portugal ao negociar a acolhida de Brizola como asilado no país. Portanto, enquanto os regimes políticos, mesmo os democráticos, tendem a classificar como "proibidas" quase todas as ações políticas de refugiados e asilados em nome do respeito à soberania estatal do estado expulsor, o governo português, na figura de Soares, chegou a "prescrever" ações aos brasileiros. Não é por acaso que o encontro de Lisboa ocorreu na sede do PSP e contou com Soares como palestrante.

A análise do processo histórico português demonstra que para Portugal, que vivia a redemocratização, interessava a conclusão do processo de transição no Brasil, haja vista que nunca se perdeu de vista a importância do Brasil enquanto parceiro político e econômico. Conforme mencionado, as relações entre Brasil e Portugal tinham, anteriormente, registrado estranhamentos por conta das diferentes posições assumidas pelos regimes políticos. Assim, inte- 
ressava "garantir" que o regime que sucederia a ditadura no Brasil fosse uma democracia, de preferência social e com um líder político simpático às novas forças políticas portuguesas, facilitando assim as relações entre os dois países.

Para garantir esse objetivo, como vimos, Soares prescrevia o repertório de ação dos exilados, determinando os canais de participação política abertos para eles. Dessa forma, não eram oferecidos canais de oportunidades políticas para exilados “extremos” em Portugal (mesmo para políticos portugueses). Tal posicionamento fica evidente na postura ambígua dos serviços de inteligência (Freire, 2010). Embora estudos empíricos em relações internacionais demonstrem que essa vinculação da democracia com a ideia de uma política exterior mais cooperativa não seja um fenômeno automático e tampouco universal, é certo que o bom relacionamento com os líderes políticos em um contexto internacional ainda marcado pela divisão entre estados nacionais importa.

Além do interesse comercial, o contexto europeu, então marcado pela emergência de atores não estatais defensores da democracia, garantia a legitimidade para que o governo português apoiasse e incentivasse a organização de uma oposição democrática à ditadura brasileira. Assim, o contexto transnacional permitiu que as forças políticas locais pudessem garantir os canais de participação aos exilados sem maiores retaliações internas ou do governo brasileiro. ${ }^{3}$ Mais do que isso, o apoio à organização partidária dos brasileiros e ao comitê pró-anistia geral no Brasil promoveu uma união da esquerda portuguesa e ajudou a fortalecer a imagem democrática do governo de Soares, segundo a publicação oficial do Comitê Brasileiro pela Anistia: ${ }^{4}$

A formação do Comitê pró-anistia geral no Brasil, em maio de 1975, conseguiu um fato raro na política portuguesa: a unidade com partidos políticos com interesses às vezes antagônicos entre si. O manifesto do lançamento do Comitê foi assinado por altos dirigentes do PS (o atual ministro da educação Solto Maior Cardia, entre outros), o PPD (Sá Carneiro), MPD/CDE e PC [...]. Desde a sua formação uma preocupação básica orientou o comitê: a de ser um organismo unitário e apartidário (Um comitê pioneiro, 1978, p. 44).

\footnotetext{
${ }^{3}$ Cabe destacar que durante o exílio de Brizola no Uruguai, por muito menos do que a criação de um partido, o governo brasileiro ameaçou cortar relações (Marques, 2006), enquanto que com Portugal manteve uma relação ambígua.

4 "Anistia" era a publicação oficial do Comitê Brasileiro pela Anistia, criado em maio de 1978 no Rio de Janeiro. O comitê reuniu diversas organizações da sociedade civil, dentre as quais destacamos o Movimento Feminino pela Anistia, movimentos ligados à Igreja Católica, entre outros. O comitê se tornou nacional e contava com comitês em diversas capitais brasileiras. Por meio dos exilados, a publicação contou a ter o apoio do Comitê pela Anistia no Brasil na França e na Bélgica. A edição de abril de 1978 é resultado dessa parceria e apresenta diversos artigos sobre o exílio em Portugal. Essa documentação está disponível para consulta na Bibliothèque de documentation internationale contemporaine (BDIC) da Universidade Paris-X (Nanterre), na França.
} 
Nesse cenário, Brizola, que havia se destacado no período anterior ao golpe enquanto um defensor dos trabalhadores, mantinha seu potencial para ser um líder desse novo regime que emergia no horizonte brasileiro, embora tivesse ultrapassado os meios legais de se fazer política. ${ }^{5}$ Permitir que ele organizasse desde o exílio um partido político significava acelerar esse processo e isso poderia ser benéfico para os portugueses, sobretudo para Mário Soares, pois poderia garantir ainda um excelente relacionamento com o próximo governo, caso o PTB ganhasse as eleições. Brizola ainda era cogitado enquanto um forte nome para os combates eleitorais (Sento-Sé, 2007).

É importante destacar também o sentimento de identificação com a luta dos brasileiros pela democratização compartilhado por boa parte da esquerda portuguesa. Esse sentimento de solidariedade ficou demonstrado não apenas na oferta do asilo político aos líderes brasileiros, mas também na participação de democratas e cantores portugueses em eventos em favor da abertura política no Brasil, como a "Semana de solidariedade com o Brasil em Lisboa", que ocorreu em 1978, as declarações de apoio em periódicos e rádios e a ampla divulgação de atividades culturais de protesto em Portugal.

Pode-se afirmar que a Semana de solidariedade com o povo brasileiro caracterizou-se por uma expressiva manifestação de solidariedade dos democratas portugueses aos que hoje no Brasil, tal como eles próprios no Portugal de antes do dia 25 de abril, lutam contra um regime assente na violência e no terror institucionalizados (Em Lisboa, 1978, p. 7).

A solidariedade era construída em torno da luta contra regimes que utilizavam de meios violentos de combate à oposição, tema que interessa à esquerda moderada portuguesa. $\mathrm{O}$ trabalhismo, que pouco dizia aos portugueses, foi interpretado por Soares como uma forma de socialismo. A aproximação com o socialismo fazia parte das propostas de criação do novo trabalhismo, transformando o PDT no primeiro partido filiado à Internacional Socialista, renovando a agenda do velho PTB, que era marcado pelo nacionalismo. No novo trabalhismo, as riquezas nacionais passariam a ser defendidas, mas em torno de uma concepção à esquerda (Sento-Sé, 2007). Devido ao contexto ditatorial brasileiro e à presença de uma esquerda democrática em Portugal, poderia dar o entendimento de um discurso meramente retórico, entretanto Sento-Sé (2007) destaca a importância de antigos militantes do Partido Socialista Brasileiro nas fileiras no novo partido.

\footnotetext{
${ }_{5}^{5}$ Podemos destacar ainda, antes do exílio, a disposição de Brizola para pegar em armas em 1961 e sua aproximação com Cuba durante o exílio no Uruguai (Marques, 2006).
} 
Leonel Brizola, que havia sido uma das mais importantes figuras do PTB no período que antecedeu o golpe de 1964, se identificava enquanto um trabalhista, ideologia que surgiu no Estado Novo (Batistella, 2013). A pesquisa documental indica que Mário Soares desempenhou importante papel nessa adoção do socialismo por Brizola. Foi inclusive por incentivo de Soares que, pouco após a sua chegada em Portugal, Brizola "foi assistir à reunião Internacional da chamada Internacional Socialista, presidida pelo líder socialdemocrata alemão Willy Brandt, parceiro de Mário Soares" (Arraes..., 1978, p. 41). Isso mostra o papel importante das redes enquanto transmissoras de valores e ideias, além da abertura de canais de participação.

Essa adoção da identidade socialista por Brizola, bem como a disposição de Brizola de não ir além dos canais de participação disponíveis, é destacada no periódico Anistia, escrito por setores da sociedade civil organizados em favor da redemocratização do Brasil em um contexto de transição:

Brizola se disse social-democrata e afirmou que, por ser amplamente favorável à anistia ampla, geral e irrestrita, deseja retornar de qualquer maneira ao Brasil e, "se necessário for, não terei nenhuma atuação que seja considerada inconveniente à concessão da anistia geral ao povo brasileiro" (Arraes..., 1978, p. 41).

Brizola se tornou o "intérprete de símbolos" adotados pelo partido que então surgia, o que o manteve como principal líder do PDT desde então. Podemos verificar ainda que essa interpretação foi resultado de uma negociação não apenas com Portugal, mas inclusive com o Brasil, que impôs condições para a abertura de canais políticos que se abriram e que apontavam para a social-democracia. $\mathrm{O}$ fato de Brizola abrir mão de qualquer forma de atuação em favor da anistia demonstra a sua disposição em negociar.

Nesse sentido, é importante destacar que segundo Vainfas (2007), no período anterior ao exílio, Brizola se encontrava em um campo da "esquerda heterodoxo". Não se considerava socialista, mas se aproximava deste por meio de temas como a defesa da classe operária, da reforma agrária e da luta antiimperialista. Para Sento-Sé (2007), a associação do trabalhismo ao socialismo apenas foi feita no exílio.

No entanto, era preciso garantir coerência aos novos valores conquistados durante o exílio. Conforme mencionado, há ganhos em termos de identidade coletiva ao promover a adaptação do partido aos novos contextos que se apresentam. Tais ganhos podem justificar a primeira tentativa de Brizola em manter a legenda ao invés de criar uma totalmente nova. Para tanto, era necessário e desejado combinar a identidade nacionalista que ajudava a 
caracterizar o PTB com a social-democracia e, ao mesmo tempo, reforçar o caráter democrático do partido, cuja história estava inegavelmente conectada ao Estado Novo de Vargas, que também produziu exilados.

Esse quadro é base do tripé "democracia, socialismo e nacionalismo" que marcou o "novo trabalhismo" proposto pelo partido por meio da Carta de Lisboa (Sento-Sé, 2007, p. 441). O tripé identificado por Sento-Sé evidencia um esforço para atribuir coerência à trajetória do PTB, unindo o nacionalismo que marca o "velho trabalhismo" com o "novo trabalhismo". O novo trabalhismo também é marcado pela defesa dos direitos humanos e das minorias, além da classe trabalhadora (Sento-Sé, 2007). Assim, a Carta de Lisboa destaca a luta em favor dos negros, dos índios e das mulheres, bandeiras que ganharam força na Europa durante a década de 1970 (Carta de Lisboa, 1979). Objetivava-se combinar a potencialidade dos ganhos advindos do fato de o PTB ser um partido conhecido pela população pela defesa dos trabalhadores com a modernidade exigida pelos novos tempos.

Dessa forma, consideramos que a solidariedade portuguesa visava não apenas favorecer relações com o futuro governo brasileiro, mas, sim, afirmar a identidade democrata do governo de Mário Soares perante sua base aliada, os demais partidos portugueses, a sociedade nacional e o cenário internacional. Além disso, ao garantir condições para a fundação de um partido por exilados, esperava-se contribuir com a crescente valorização da social-democracia e dos direitos humanos no mundo, para assim deslegitimar as forças conservadoras em Portugal.

\section{Considerações finais}

A análise da fase genética do PDT confirma que o exílio pode influenciar o jogo político interno. Ele se tornou parte da história de importantes líderes políticos brasileiros. Uma vez de volta ao Brasil, Brizola procurou guiar um partido de acordo com os valores aprendidos, partido este criado durante o exílio em Portugal por meio da solidariedade de membros da elite política e da sociedade portuguesa, visando garantir coerência à sua trajetória.

Nesse sentido, é importante destacar que as solidariedades são parte de um jogo político transnacional (Devin, 2004). Logo, a partir da análise do contexto português e mundial, pode-se observar que o apoio português à transição democrática brasileira se baseava nas relações entre os atores domésticos (fortalecida pelo contexto de exílio de importantes membros da elite política), na crescente valorização da democracia no cenário português e mundial e, por fim, no consenso nacional e europeu em torno da condenação dos regimes políticos acusados de institucionalizar o uso da violência contra 
seus opositores. A Carta de Lisboa se alinha a esse processo e evidencia a adesão de novos valores pelos exilados brasileiros ao divulgar uma nova reinterpretação do trabalhismo, que, além de defender o nacionalismo e a democracia, adere ao socialismo e à defesa de minorias.

Com efeito, a análise indicou que embora seja evidente a importância da liderança carismática assumida por Brizola - evidenciada tanto com a abertura dos canais no governo português quanto no sucesso em reunir a esquerda trabalhista exilada em Lisboa -, o líder trabalhista foi obrigado a negociar no exílio. A ampliação dos canais de oportunidades ofertada a Brizola e aos exilados em sua volta foi direcionada para a organização política por meio de partidos e para a social-democracia. Além disso, limites para o alcance dessa atuação foram negociados entre Brasil e Portugal. Esse quadro o tornou uma liderança situacional do partido durante o exílio, diferentemente da posição que assumiu no partido ao retornar ao país, o que comprova que o jogo político no exílio é particular e marcado pelo contexto transnacional.

\section{Referências}

ALVES, Maria Helena Moreira. Estado e oposição no Brasil (1964-1984). Bauru: Edusc, 2005.

ARRAES, Brizola e Julião: os três mais famosos. Anistia, p. 41, São Paulo, abr. 1978. BDIC, Archives. F Delta 1119 (1-2). Recueil: Répression et Droits de l'homme au Brésil. Documents divers: 1969-1986.

BATISTELLA, Alessandro. O trabalhismo getulista-reformista do antigo PTB e o "novo trabalhismo" do PDT: continuidades e descontinuidades. Aedos, v. 5, n. 12, p. 116-132, 2013.

CARTA de Lisboa. Lisboa, 17 de junho de 1979 <http://pdt12.locaweb.com.br/ memoria.asp?id=17> (15 jan. 2016).

CARVALHO, Thiago. O Brasil e o fim do império português. In: Miguel Bandeira Jerónimo; António Costa Pinto (orgs.). Portugal e o fim do colonialismo. Lisboa: Edições 70, 2014. p. 155-178.

CONSTITUINTE, abertura, novos partidos. Anistia. São Paulo, abr. 1978. p. 43. BDIC, Archives: F Delta 1119 (1-2). Recueil: Répression et Droits de l'homme au Brésil. Documents divers: 1969-1986.

D'ARAÚJO, Maria Celina. Sindicatos, carisma e poder: o PTB de 1945 a 1965. Rio de Janeiro: Fundação Getulio Vargas, 1996.

DAHL, Robert. Poliarquia. São Paulo: Edusp, 1997.

DEVIN, Guillaume. Introduction: les solidarités transnationales, phénomène social à l'échelle mondiale. In: Guillaume Devin (org.). Les solidarités transnationales. Paris: L'Harmattan, 2004. p. 17-18. 
EM LISBOA, semana de solidariedade com o Brasil. Anistia. São Paulo, abr. 1978. p. 07. BDIC, Archives: F Delta 1119 (1-2). Recueil: Répression et Droits de l'homme au Brésil. Documents divers: 1969-1986.

FORTI NETO, Octavio. Partidos políticos transnacionais: elementos para uma possível definição. In: IV Encontro Nacional da Associação Brasileira de Relações Internacionais (Abri). Anais... Belo Horizonte, 2013 <www.encontronacional2013. abri.org.br> (24 jan. 2016).

FREIRE, Américo. Ecos da estação Lisboa: o exílio das esquerdas brasileiras em Portugal. Sociologia, problemas e práticas, n. 64, p. 37-57, $2010<10.7458 /$ SPP2010647783>.

GONÇALVES, Leandro Pereira. Entre Brasil e Portugal: trajetória e pensamento de Plínio Salgado e a influência do conservadorismo português. São Paulo, 2012. Tese de doutorado em História, Pontifícia Universidade Católica de São Paulo.

JUBILUT, Liliana Lyra. O direito internacional dos refugiados e sua aplicação no ordenamento jurídico brasileiro. São Paulo: Método, 2007.

KAISER, Karl. Transnational politics: toward a theory of multinational politics. International Organization, v. 25, n. 4, p. 790-817, 1971<1017/S0020818300017732>.

MARQUES, Teresa Cristina Schneider. Militância política e solidariedades transnacionais: a trajetória política dos exilados brasileiros no Chile e na França (1964-1979). Porto Alegre, 2011. Tese de doutorado em Ciência Política, Programa de Pós-Graduação em Ciência Política, Universidade Federal do Rio Grande do Sul.

MARQUES, Teresa Cristina Schneider. Ditadura, exílio e oposição: os exilados brasileiros no Uruguai (1964-1968). Cuiabá, 2006. Dissertação de mestrado em História, Programa de Pós-graduação em História, Universidade Federal de Mato Grosso.

NORONHA, Ricardo. Lutas sociais e nacionalizações (1974-75): A banca ao serviço do povo. In: Raquel Varela; Ricardo Noronha; Joana Dias Pereira. Greves e conflitos sociais em Portugal. Lisboa: Colibri, 2012. p. 225-236.

PANEBIANCO, A. Modelos de partido: organização e poder nos partidos políticos. São Paulo: Martins Fontes, 2005.

PINTO, António Costa. A vida política. In: António Costa Pinta (org.). A busca da democracia: 1960-2000. Lisboa: Objectiva; Fundación Mapfre, 2015. p. 25-54.

REZOLA, Maria Inácia. 25 de Abril: mitos de uma revolução. Lisboa: Esfera dos Livros, 2011.

RIBEIRO, Pedro Floriano. Realismo e utopia em Michels. Revista Sociologia e Política, v. 20, n. 44, p. 31-46, $2012<10.5380 /$ rsp.v20i44.34418>.

RONIGER, Luis. Exílio massivo, inclusão e exclusão política no século XX. Dados - Revista de Ciências Sociais, Rio de Janeiro, v. 53, n. 1, p. 91-123, $2010<10.1590 /$ S0011-52582010000100004>.

SECCO, Lincoln. A Revolução dos Cravos e a crise do império colônia português: economias, espaços e tomadas de consciência. São Paulo: Alameda, 2004. 
SENTO-SÉ, João Trajano. Um encontro em Lisboa: o novo trabalhismo do PDT. In: Jorge Ferreira; Daniel Aarão Reis (orgs.). Revolução e democracia (1964-...). Rio de Janeiro: Civilização Brasileira, 2007. p. 429-450.

SOARES, Mário. Depoimento. In: Refundação do trabalhismo. 25 maio 2011. < https:// www.youtube.com/watch?v=xhKQ5EJUVCM\&feature=youtube> (23 fev. 2016).

TILLY, Charles; TARROW, Sidney. Politique(s) du conflit: de la grève à la révolution. Paris: Presses de Sciences Po, 2008.

UM COMITÊ pioneiro. Anistia. São Paulo, abr. 1978. p. 44. BDIC, Archives: F Delta 1119 (1-2). Recueil: Répression et Droits de l'homme au Brésil. Documents divers: 1969-1986.

VAINFAS, Ronaldo. A luz própria de Leonel Brizola: do trabalhismo getulista ao socialismo moreno. In: Jorge Ferreira; Daniel Aarão Reis (orgs.). Revolução e democracia (1964-...). Rio de Janeiro: Civilização Brasileira, 2007. p. 479-502.

Autor corresponde:

Leandro Pereira Gonçalves

Av. Ipiranga, 6681 - Partenon

90619-900 Porto Alegre, RS, Brasil

Recebido em: 4 abr. 2016

Aprovado em: $1^{\circ}$ set. 2016 